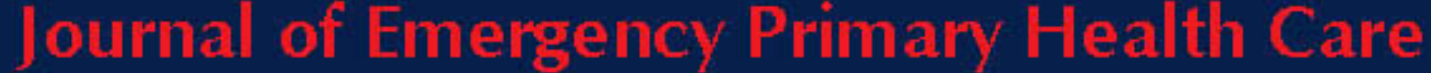

An International elournal of Prehospital Care Research, Education, clinical Practice, Policy and Service Delivery

\title{
OBITUARY
}

\section{Rob Bland and Philip Oakley}

On the $2^{\text {nd }}$ of January 2004, Ambulance Paramedic Rob Bland and Student Ambulance Paramedic Phil Oakley were tragically killed whilst responding to an emergency call.

Rob Bland had been employed by the Metropolitan Ambulance Service for 23 years and during that time primarily worked at the Northcote, and in recent years, at the Healesville ambulance branches.

"I first met Rob just after he started and was allocated to Preston Branch to undertake his first operational on road experience as a student. I recall fondly of him as a quiet but intensely caring person. Over the years, as I watched Rob's progress along the road of life, I developed the view that the ambulance service unknowingly contributed to his humanity and conviction for those less privileged and in need and despair. Often, his personal actions to become involved in others would be to his own disadvantage. However, these generous acts of care both inside and outside ambulance were inspiring to all of us who new him. Rob had a deep and sincere spirituality, and his Christian beliefs and convictions were the foundation for his thoughts and behaviours as an ambulance worker and private person. He is sadly missed, and left behind a true legacy of humanity and care”. - David Shugg

Philip Oakley was also employed by the Metropolitan Ambulance Service and was a student at the Monash University Centre for Ambulance and Paramedic Studies, completing the final stages of his Diploma.

"Philip was particularly popular with both his classmates and the staff of MUCAPS. Whilst Philip was not an academic high achiever, clinically he pursued excellence and this was clearly evident to all who had the pleasure of working with him. The qualities that made Philip the person he was were his sense of humour and his exceptional communication skills. Philip was a very 'down to earth 'person and quickly engendered a sense of life-long friendship in those who came into close contact with him. His sense of humour often saw him visiting his lecturers' offices for a 'please explain' - but it was always difficult to keep a straight face. He was always the first to recognise his own faults and the first to forgive faults in others. Philip will be sadly missed but long remembered”. - Mark Chilton

Both officers were farewelled at large funerals with full service honours. In addition to the bonds as colleagues in the ambulance service, Rob and Philip shared another exceptional bond of generous community service, in addition to and outside their ambulance duties. In recognition of this exceptional commitment, MUCAPS in partnership with the Metropolitan Ambulance Service and Rural Ambulance Victoria, and with the approval and support of both their families, have initiated the Bland/Oakley Community Service Award to commemorate all ambulance paramedics who have died in the course of active duty. 
The award will be presented once a year at the Monash graduation ceremony in December. All Monash University Paramedic students who graduate during the year will be eligible for the December award.

The award is for the Student Ambulance Paramedic who provides the highest level of community service outside the normal operational function of a Student Ambulance Paramedic.

Nominations will be from the student's peers. The first award will be conferred in December 2004.

David Shugg and Mark Chilton

Further information and nomination forms for the Bland/Oakley Community Service Award can be obtained from mark.chilton@med.monash.edu.au 